\title{
SYNTHESIS, SPECTRAL, AND PHARMACOLOGICAL EVALUATION OF 3 AND 5 SUBSTITUTED 2,4-THIAZOLIDINEDIONE DERIVATIVES
}

\author{
NAVJOT SINGH SETHI ${ }^{*}$, DN PRASAD ${ }^{2}$, DEEPAK BHAGWAT ${ }^{1}$, ANURADHA KUMARI ${ }^{3}$, MADHU SHARMA ${ }^{3}$, \\ SANGEETA KAUNDAL ${ }^{3}$
}

${ }^{1}$ Department of Pharmacy, Maharaja Agrasen University, Solan, Himachal Pradesh, India. ${ }^{2}$ Shivalik College of Pharmacy, Maujowal, Punjab, India. ${ }^{3}$ Himachal Institute of Pharmaceutical and Educational Research, Nadaun, Himachal Pradesh, India. Email: sethinavjot17@yahoo.com

Received: 03 April 2016, Revised and Accepted: 23 July 2018

ABSTRACT

Objective: 2,4-Thiazolidinedione derivatives was launched as antidiabetics in 90's. Later the derivatives of 2,4-thiazolidinedione were banned due to hepatotoxicity. To the date, much research has been directed toward the synthesis and novel uses of 2,4-thiazolidinedione compounds. The aim of the present study is to synthesize a set of 3,5-disudstituted-2,4-thiazolidinediones as antimicrobial. These compounds were evaluated for their antimicrobial activity.

Method: First, the 2,4-thiazolidinedione was substituted at the position of 3 using sodium hydroxide and ethanol and then substituted at the position of 5 in the presence of piperdine by the Knoevenagel condensation method. The structures of the compounds were established on the basis of infrared and nuclear magnetic resonance spectral studies.

Result: 3,5-disubstituted-5-benzylidine-2,4-thiazolidinediones derivative was synthesized using benzyl halides and aromatic aldehydes. The results obtained showed that TZ-1 exhibited good activity against Bacillus subtilis while no activity against Escherichia coli.

Conclusion: Attachment of more heterocyclic rings containing Nitrogen on the $3^{\text {rd }}$ position of 2,4-thiazolidinedione can enhance the antimicrobial activity. Addition of more lipophilic agents may increase the bioavailability and efficacy of the drug. Long alkyl chains on the benzylidene ring can also increase the lipophilic character, and further attachment of these kind of agents on benzylidene chain may produce safe and effective compounds in future.

Keywords: 2,4-TZD, Antimicrobial, E.coli,Knovenegel condensation, 3 and 5 disubstituted 2,4-TZD

(C) 2018 The Authors. Published by Innovare Academic Sciences Pvt Ltd. This is an open access article under the CC BY license (http://creativecommons. org/licenses/by/4. 0/) DOI: http://dx.doi.org/10.22159/ajpcr.2018.v11i11.12008

\section{INTRODUCTION}

The increasing identification of antibiotic-resistant pathogens that cause serious infections cannot be ignored. Although the future cannot be predicted with certainty, it is surely possible that an extensive epidemic of resistant bacterial infections could potentially harm millions of people. Given that it takes more than 10 years to establish the efficacy and safety of new compounds, there is an urgent need to restock the antibiotic pipeline. As various infections are the medical challenge, such as gastrointestinal tract GIT infections, HIV, Hepatitis C and urinary tract infections, and the 2,4-thiazolidinediones can be the key to the problem. Due to the resistance and many side effects of antibiotics being used, there is a need for new antimicrobials. Like penicillin has severe side effects, i.e., anaphylaxis and GIT disturbance, and due to acid liability of penicillin, it cannot be given orally. However, 2,4-thiazolidinedione derivatives resemble penicillin's heterocyclic ring but has no acid liability and can be given orally in various infections. Hence, the valuable properties of 2,4-thiazolidinedione compel to synthesize its various derivatives by substituting at position 3 and 5 [1-4]

Why 2,4-thiazolidinedione derivative is chosen for antimicrobial activity.

There are some reasons because of which this nucleus is chosen for antimicrobial activity.

- 2,4-thiazolidinedione has nitrogen in the heterocyclic ring. It has been proved that whenever nitrogen is present as the member of the heterocyclic ring, it must have antimicrobial activity, for example, beta-lactam ring of penicillin and quinoline and isoquinoline.

- 2,4-Thiazolidinedione is the new antimicrobial which will decrease the chances of resistance $[5,6]$

Scheme of synthesis

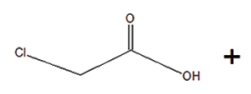

Chloroacetic Acid

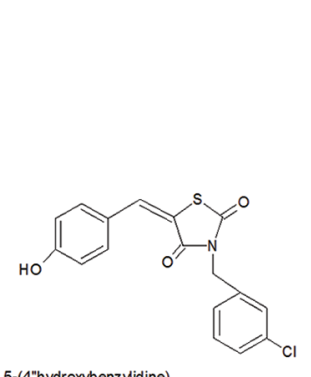

5-(4"hydroxybenzyidine)

(1)<smiles>N=C(N)N</smiles>
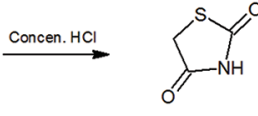

2,4-Thiazolidinedione
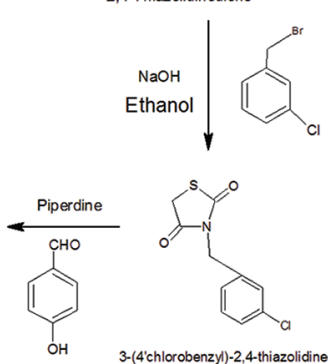

ne $\quad$ ne $(4$

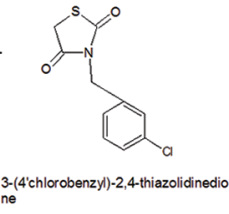

In scheme, the formed 2,4-TZD first reacted with substituted benzyl halide instead of substituted benzaldehyde, and the N-substituted-2,4TZDs are reacted with substituted benzaldehyde, and other 2,4-TZD derivatives are the main products.

The synthesized compounds were then evaluated for their pharmacological activity. For antimicrobial activity, all compounds were taken and were evaluated using cup plate method against Bacillus subtilis and Escherichia coli. Ciprofloxacin was taken as standard and zone of inhibition was measured. The title compounds were synthesized by Knoevenagel condensation and substitution reactions. The synthesized compound was then evaluated for its antimicrobial activity $[4,7]$. 


\section{MATERIALS AND METHODS}

Materials

1. All the chemicals used were procured from C.D.H and HiMedia and purified before use.

2. Melting points were determined on the open capillary tube on Campbell Melting Point Apparatus and are uncorrected.

3. The silica gel used for thin layer chromatography (TLC) was "silica gel G" procured from Merck and was coated on laboratory glass slides.

4. TLC plates were visualized using an iodine chamber

5. Infrared (IR) spectra were taken using Fourier transform IR Thermo scientific; NICOLET Is10 and $\mathrm{KBr}$ disk spectrophotometer. Only principal peaks are reported and expressed in $\mathrm{cm}^{-1}$.

6. Proton nuclear magnetic resonance spectra (1H NMR) were recorded on Bruker AC 300 F, 300 MHz spectrophotometers. Chemical shifts are expressed as $\delta$ value (ppm), downfield from tetramethylsilane used as internal standard.

7. While citing $1 \mathrm{H}$ NMR data, the following abbreviations have been used S (singlet), d (doublet), t (triplet), and m (multiplet).

\section{Methods}

\section{Drying of ethanol}

Ethanol of high degree of purity is conveniently obtained by dehydrating commercial ethanol with calcium oxide. In $500 \mathrm{ml} \mathrm{RB}$ flask, poured the content of the commercially obtained ethanol, to it add $1 \mathrm{~g}$ of calcium oxide and allowed for refluxing. It was then distilled and collected for further use.

\section{Drying of toluene}

Commercial toluene may contain methyl thiophenone, which cannot be removed by distillation. It can be purified by treating with concentrated sulfuric acid, but care was taken that temperature was not allowed to rise unduly $\left(<30^{\circ} \mathrm{C}\right)$ as toluene is sulfonated more easily than benzene and then store the dry toluene over sodium wire, phosphorus pentaoxide, or calcium hydride.

\section{Drying of acetone}

To the $700 \mathrm{ml}$ acetone contained in a liter bottle, a solution of $3 \mathrm{gm}$ of silver nitrate in $20 \mathrm{ml}$ of water as added followed by $10 \mathrm{ml}$ of $1 \mathrm{M} \mathrm{NaOH}$ solution, and the mixture was shaken for about $10 \mathrm{~min}$. The mix was then filtered dried with calcium sulfate and distilled [7].

\section{Experimental work [7-10]}

Step 1: Synthesis of 2,4-thiazolidinedione<smiles>O=C(O)CCl</smiles>

Ohloroactic acid

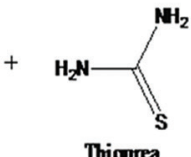

Thiourea

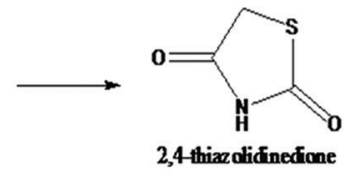

\section{Procedure}

In a $250 \mathrm{ml}$ three-necked flask a solution containing $56.4 \mathrm{~g} 0.6$ mole of chloroacetic acid in $60 \mathrm{ml}$ of water and $45.6 \mathrm{~g}$ ( 0.6 moles) of thiourea dissolved in $60 \mathrm{ml}$ of water. The mixture was stirred for $15 \mathrm{~min}$. To the contents of the flask were now added slowly $60 \mathrm{ml}$ concentrated hydrochloric acid from dropping funnel, after which the reaction mixture was stirred and refluxed for $10-12 \mathrm{~h}$ at $100-110^{\circ} \mathrm{C}$. On cooling, the contents of the flask solidified to a mass of clusters of white needles. The product was filtered and washed with water to remove traces of hydrochloric acid and dried. It was re-crystallized from ethanol.

Yield: $85 \%$

Synthesis of 3-(4'chlorobenzyl)-2, 4-thiazolidinedione

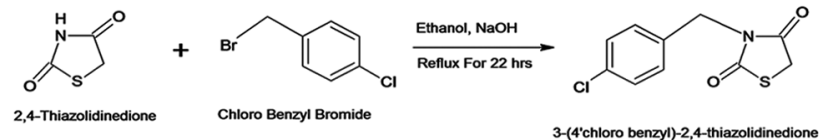

\section{Step 2: Procedure}

In a $250 \mathrm{ml} \mathrm{RBF}, \mathrm{NaOH}(0.8 \mathrm{~g}, 0.02$ moles $)$ was dissolved in $20 \mathrm{ml}$ ethanol. To this solution, 2, 4-thiazolidinedione (0.02 moles) and benzyl bromide were $(0.02$ moles $)$ added. The resulting reaction mixture was then refluxed for $40 \mathrm{~h}$. Precipitation of salt was observed during the reaction. At the end of the reflux period, ethanol was distilled out, and the residue was extracted from ether and water. The ethereal layer was removed, dried over sodium sulfate and concentrated. The product was dried under reduced pressure and was re-crystallized from ethanol.

Yield: $84.45 \%$; m.p: $97-99^{\circ} \mathrm{C}$

TLC: Benzene: Ethyl acetate (4.5:0.5); $\mathrm{R}_{\mathrm{f}}$ 0.64.

Synthesis of 5-benzylidene-N-substituted-2,4-thiazolidinedione derivatives

Synthesis of 5-(4"hydroxy benzylidene)-3-(4' chlorobenzyl)-2,4thiazolidinedione

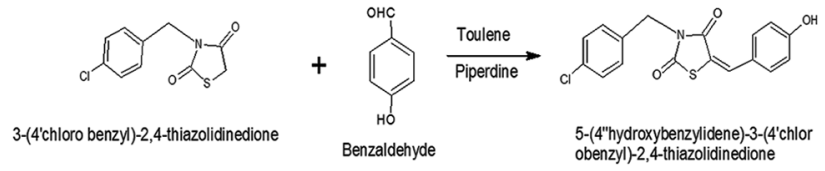

\section{Procedure}

In a $250 \mathrm{ml} 3$-necked round bottom flask provided with a DeanStark apparatus, 4-hydroxy benzaldehyde $(0.188$ moles $)$ and 3-chlorobenzyl-2, 4-thiazolidinedione $(0.188$ moles $)$ were together suspended in dry toluene. To this catalytic amount of piperidine $(1 \mathrm{ml})$ was added. The mixture was refluxed with stirring. After complete removal of water and when the temperature crossed $110^{\circ} \mathrm{C}$ the reaction mixture was stirred for further $1 \mathrm{hr}$. On cooling, the product precipitated out of toluene. The compound was filtered and washed with cold, dry toluene, and dry ethanol.

\section{Yield: $72 \%$}

Melting point $-205^{\circ} \mathrm{C}$

TLC of 5-(4'hydoxybenzylidene)-3-(4' chlorobenzyl)-2,4thiazolidinedione (Table 1)

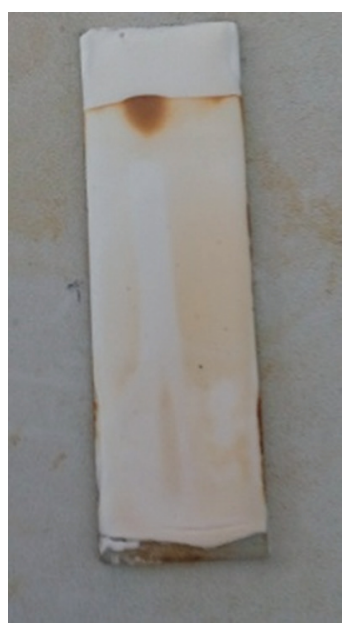

Rf value: 0.61

Table 1: Characterization data of the synthesized compound

\begin{tabular}{llll}
\hline Compound & Yield (\%) & Melting point & Rf. value \\
\hline $\mathrm{TZ}-1$ & 66 & $205^{\circ} \mathrm{C}$ & 0.16 \\
\hline
\end{tabular}


Spectral analysis

NMR study of 5-(4"hydoxy benzylidene)-3-(4'chlorobenzyl)-2,4thiazolidinedione (TZ-1)

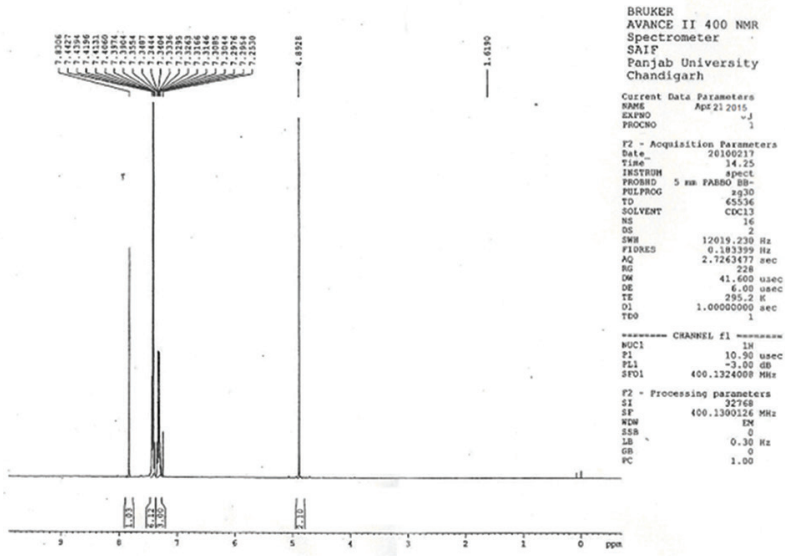

NMR: $\delta 4.89$ (s,2H,CH2), $\delta 7.25-7.44(\mathrm{~m}, 9 \mathrm{H}, \mathrm{ArH}), \delta 7.83(\mathrm{~s}, 1 \mathrm{H}, \mathrm{OH})$

IR study of 5-(4"hydoxy benzylidene)-3-(4'chlorobenzyl)-2,4thiazolidinedione

IR of 5-(4"-hydroxybenzylidene)-3-(4'chlorobenzyl)-2,4-TZD (TZ-1) (Table 2)

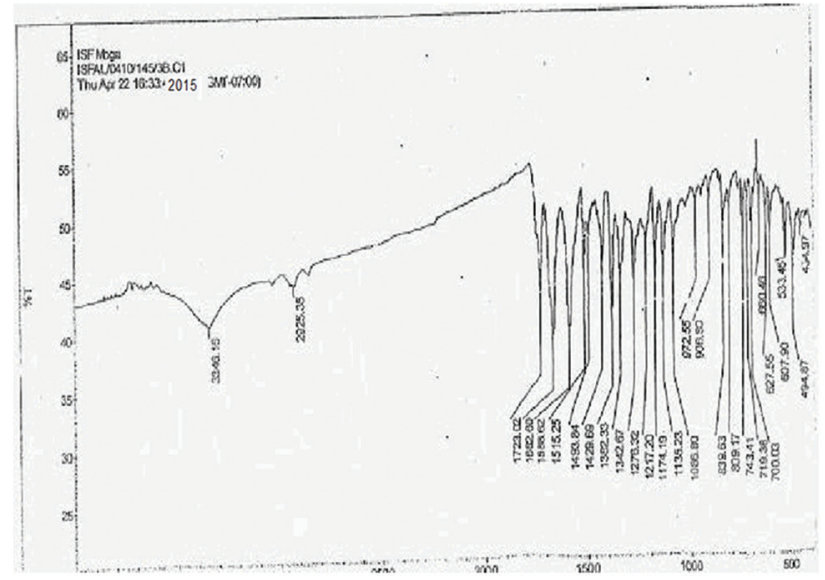

Pharmacological activity

We determined 2,4 thiazolidinedione as antimicrobial using the cup plate method. We found very interesting results of inhibition of the growth of Gram-positive as well as Gram-negative bacteria.

\section{Pharmacological activity}

Antimicrobial activity [11-13]

Various therapeutic agents which show inhibition of growth of microorganisms such as antibiotics or essential for their growth such as vitamins and amino acids are standardized by microbiological assays.

Any change in the antibiotic molecule which may not be detected by chemical methods will be revealed by a change in the antimicrobial activity, and hence microbiological assays are very useful for resolving doubts regarding a possible change in potency of antibiotics.

The minimal assay is based on a comparison of the inhibition of growth of microorganisms by measured concentrations of the antibiotic to be examined with that produced by known concentrations of a standard preparation of the antibiotic having the known activity.

Two general methods are used for microbiological assays of antibiotics: Method A: Cylinder plate method or cup plate method

Method B: Turbidimetric method or tube assay method.

The cylinder plate method depends on diffusion of the antibiotic from the vertical cylinder through a solidified agar layer in Petri plate to an extent such that growth of the added microorganisms is prevented entirely in a zone around the cylinder containing a solution of the antibiotics.

The turbidimetric method depends on the inhibition of growth of microbial culture in a uniform solution of antibiotic in a fluid that is favorable to its rapid growth in the absence of the antibiotic.

Minimum inhibitory concentration is defined as the lowest concentration of an antibacterial that will inhibit the visible growth of microorganisms, and minimum bactericidal concentration is the lowest concentration of antibacterial that will prevent the growth of microorganisms after subculture antibiotic-free media. Any compound showing inhibition zone exceeding $9 \mathrm{~mm}$ diameter and quality of zone better or comparable to ciprofloxacin is considered to be endowed with antibacterial potential.

\section{Procedure}

Antimicrobial activity of the synthesized 3,5-disubstituted thiazolidinediones derivative was carried out using cup plate method. The compounds were tested against stain of B. subtilis and E. coli. Stock solution of the synthesized compounds was prepared in dimethyl sulfoxide (DMSO), and the ciprofloxacin was prepared in distilled water. Dilution of the stock solution of synthesized compound was done using DMSO and $3000 \mu \mathrm{g} / \mathrm{ml}$ concentration was prepared in micro test tubes. The stock solution of standard, i.e., ciprofloxacin was diluted in sterile water to give a concentration of $100 \mu \mathrm{g} / \mathrm{ml}$.

$100 \mu \mathrm{l}$ organism suspensions were seeded on culture plates. Then, in each, the agar plate cavities/well $(9 \mathrm{~mm})$ was prepared using a cork borer. $100 \mu \mathrm{l}$ of the compound was transferred to the wells and ciprofloxacin $(100 \mu \mathrm{g} / \mathrm{ml})$ was added to the remaining well. The plates were incubated at $30^{\circ} \mathrm{C}$. The plates were observed for growth at the end of 24-48 $\mathrm{h}$ and the zone of inhibition was measured.

Petri dishes showing inhibition zone against $B$. subtilis (a) and E. coli (b)

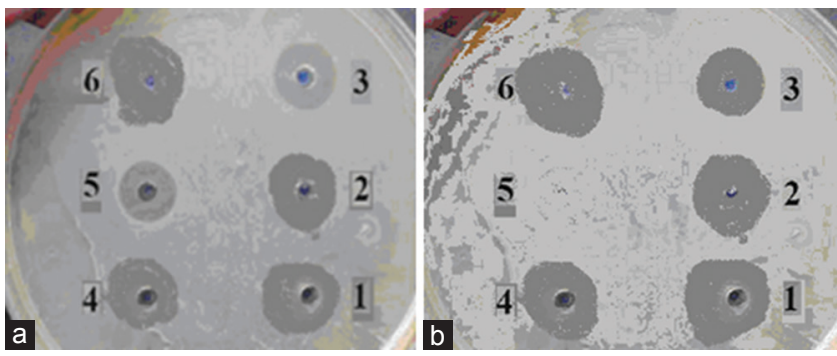

Table 2: IR and 1HNMR data

\begin{tabular}{llll}
\hline S. No & Molecule code & IR (cm $\left.^{-1}\right)$ & 1H NMR (ppm) \\
\hline 1 & TZ-1 & $1732.12,1336.77,1082.43,3036.31,1603.83,1493.82,2955.00$ & $3.89(\mathrm{~s}, 1 \mathrm{H}), 4.89(\mathrm{~s}, 2 \mathrm{H}), 7.24-7.50(\mathrm{~s}, 10 \mathrm{H})$ \\
\hline
\end{tabular}

IR: $1723.02 \mathrm{~cm}^{-1}$ (Ketone, C=0), $1588.62 \mathrm{~cm}^{-1}$ and $1493.84 \mathrm{~cm}^{-1}$ (Aromatic C=C), $3346.16 \mathrm{~cm}^{-1}$ (Phenolic OH), $2925.35 \mathrm{~cm}^{-1}$ (Alkane, C-H), $1342.67 \mathrm{~cm}^{-1}-$

$1086.80 \mathrm{~cm}^{-1}$ (Amine C-N). IR: Infrared, 1H NMR: Proton nuclear magnetic resonance spectra 
Table 3: Antibacterial activity (in vitro) against Gram-positive and Gram-negative bacteria

\begin{tabular}{llll}
\hline S. No & Compound & Zone of inhibition against $\boldsymbol{B}$. subtilis $\mathbf{( m m})$ & Zone of inhibition against $\boldsymbol{E}$. coli $(\mathbf{m m})$ \\
\hline 1 & TZ-1 & 17 & 00 \\
2 & Ciprofloxacin & 22 & 21 \\
\hline B. subtilis: Bacillus subtilis, E. coli: Escherichia coli & &
\end{tabular}

The number 5 (Fig. a and $b$ ) is the zone of inhibition shown by 5-(4"-hydroxybenzylidene)-3-(4'chlorobenzyl)-2,4-TZD on both Grampositive and Gram-negative bacteria. The no. 6 (Fig. a and b) is the zone of inhibition by standard drug ciprofloxacin.

A set of negative and positive controls of growth were also kept for incubation along with test plates. In the plate, for negative growth, the highest volume of DMSO and sterile distilled water was used with no culture being seeded, while in the plate representing maximum growth (positive control), the highest volume of DMSO and sterile distilled water was used along with the organism.

\section{Graphical representation of antimicrobial activity}

Activity against B. subtilis

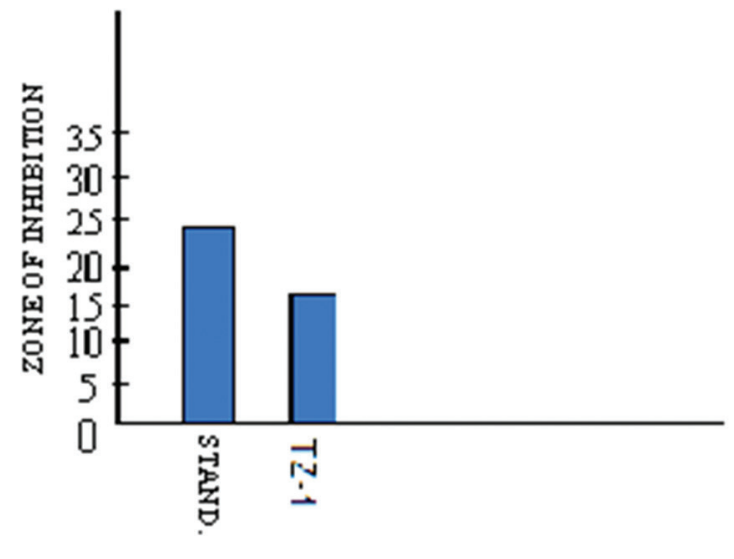

SYN THESIZED COMPQUNDS

Activity against E. coli (Table 3)

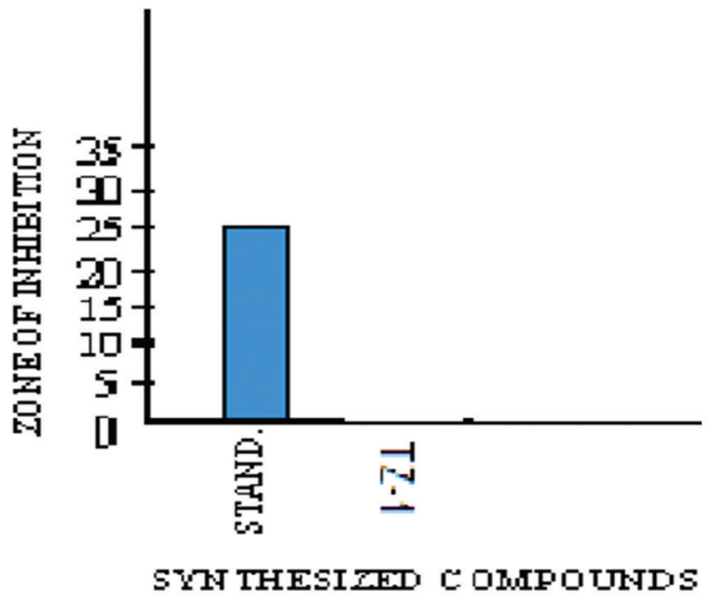

\section{RESULTS}

The derivative 5-(4"'-hydroxybenzylidene)-3-(4'chlorobenzyl)2,4-TZD (TZ-1) was found to be active against only Gram-positive bacteria (B. subtilis) but showed no activity against Gram-negative bacteria (E. coli). TZ-1 showed remarkable activity against Grampositive bacteria but less effective than ciprofloxacin used as reference drug.

\section{SUMMARY AND DISCUSSION}

3,5-disubstituted-5-benzylidine-2,4-thiazolidinediones derivative was synthesized using benzyl halides and aromatic aldehydes. Synthesized compound was characterized by chromatographic methods, IR spectroscopy, and NMR spectroscopy for their structural confirmation. This compound was tested for antimicrobial activity.

Antimicrobial evaluation of the compound was done against $B$. subtilis and E. coli using Cup Plate method. The results obtained showed that TZ-1 exhibited good activity against $B$. subtilis while no activity against E. coli.

\section{CONCLUSION}

Due to some disadvantages of long reaction times, use of large quantities of volatile organic and harsh conditions, therefore, development of an efficient and versatile method is still required.

The work on this project was started with the objective of synthesizing some known 2,4-thiazolidinedione by different methods as reported in literature. Further modifications on benzylidene ring and nitrogen of the 2,4-thiazolidinedione ring may increase antimicrobial activity. Attachment of more lipophilic agents may increase the bioavailability and efficacy of the drug.

Long alkyl chains on the benzylidene ring can also increase the lipophilic character, and further attachment of these kind of agents on benzylidene chain may produce safe and effective compounds in future.

\section{ACKNOWLEDGMENT}

The author wishes to acknowledge the Director of School of Pharmacy, Maharaja Agrasen University, Kalujhanda, for providing the chemicals and Labs and Panjab University, Chandigarh, for providing IR and NMR data.

\section{AUTHOR'S CONTRIBUTIONS}

Navjot Singh Sethi: Performed the experiments. D. N. Prasad: Conceived the idea, study design, and finalized the manuscript. Deepak Bhagwat: Performed the clinical studies and helped in the preparation of manuscript. Anuradha, Madhu, and Snageeta: Assisted in experimental work and helped in Statistical Evaluation and Preparation of the manuscript.

\section{CONFLICTS OF INTERESTS}

There are no conflicts of interest.

\section{REFERENCES}

1. Bozdağ-Dündara $\mathrm{O}$, Özgenb $\mathrm{O}$, Menteşea A, Altanlarc N, Atlıc $\mathrm{O}$, Kendib E, et al. Synthesis and antimicrobial activity of some new thiazolyl thiazolidine-2, 4-dione derivatives. Bioorg Med Chem 2007;15:6012-7.

2. Kumar KS, Reddy BM, Babu VH. Synthesis of some novel 2, 4-thiazolidinedione incorporated pyrazole derivatives as anti-cancer agents. Int J Pharm Pharm Sci 2014;6:831-4.

3. Rekha S, Shantharam U. Synthesis and evaluation of novel thiazolidinediones for anti-diabetic activity. Int J Pharm Pharm Sci 2011:3:113-7.

4. Sachin M, Prabhat UK, Sandeep M. Thiazolidinediones: A Plethro of biological Load. Int J PharmTech Res 2011;3:62-75.

5. Hussein HS, Sakuma T. Prevalence of Shiga toxin-producing 
Escherichia coli in dairy cattle and their products. J Dairy Sci 2004;88:450-65.

6. De Ryk CA, Maglio D, Nicolau DP. Defining the need for new antimicrobials: Clinical and economic implications of resistance in the hospitalised patient. Expert Opin Pharmacother 2005;6:873-89.

7. Bradsher CK, Brown FC, Sinclair EF. Some analogs of 3-benzylrhodanine. J Am Chem Soc 1956;78:6189-91.

8. Labouta IM, Salama HM, Eshba NH, Kader O, El-chrbini E. Potential anti-microbial: Syntheses and in vitro anti-microbial evaluation of some 5-arylazo-thiazolidones and related compounds. Eur J Med Chem 1987;22:485-9.

9. Bozdağ-Dündar O, Verspohl EJ, Daş-Evcimen N, Rebecca M, Bauer KK, Sarıkaya M, et al. Synthesis and biological activity of some new flavonyl-2,4-thiazolidinediones. Bioorg Med Chem 2008; 16:6747-51.

10. Youfu L, Hao M, Zhzhi Z, Yuquan W. Discovery of (z)-5-(4methoxybenzylidine) yhiazolidine-2,4-dione, a readily available and orally active glitazones for the treatment of concanavalin a-induced acute liver injury of BALN/c mice. J Med Chem 2010; 53:273-81

11. Donald JA. Burger's Medicinal Chemistry and Drug Discovery. Ch-1. New Jersey: John Wiley and Sons, Inc.; 2003. P. 1-43.

12. Steven PT, Parker TT, Jerry RC, Roberta MF. Synthesis and biological activity of the metabolites. J Med Chem 1996;39:5053-63.

13. Dubey RC, Maheshwari DK. Practical Microbiology. New Delhi: S. Chand and Company; 2004. P. 1-56. 